\title{
Catastrophic degradation of the interface of epitaxial silicon carbide on silicon at high temperatures
}

Aiswarya Pradeepkumar, Neeraj Mishra, Atieh Ranjbar Kermany, John J. Boeckl, Jack Hellerstedt, Michael S. Fuhrer, and Francesca lacopi

Citation: Appl. Phys. Lett. 109, 011604 (2016); doi: 10.1063/1.4955453

View online: http://dx.doi.org/10.1063/1.4955453

View Table of Contents: http://aip.scitation.org/toc/apl/109/1

Published by the American Institute of Physics

\section{Articles you may be interested in}

Comment on "Catastrophic degradation of the interface of epitaxial silicon carbide on silicon at high temperatures" [Appl. Phys. Lett. 109, 011604 (2016)]

Appl. Phys. Lett. 109, 196101196101 (2016); 10.1063/1.4967224

Response to "Comment on 'Catastrophic degradation of the interface of epitaxial silicon carbide on silicon at high temperatures'” [Appl. Phys. Lett. 109, 196101 (2016)]

Appl. Phys. Lett. 109, 196102196102 (2016); 10.1063/1.4967228

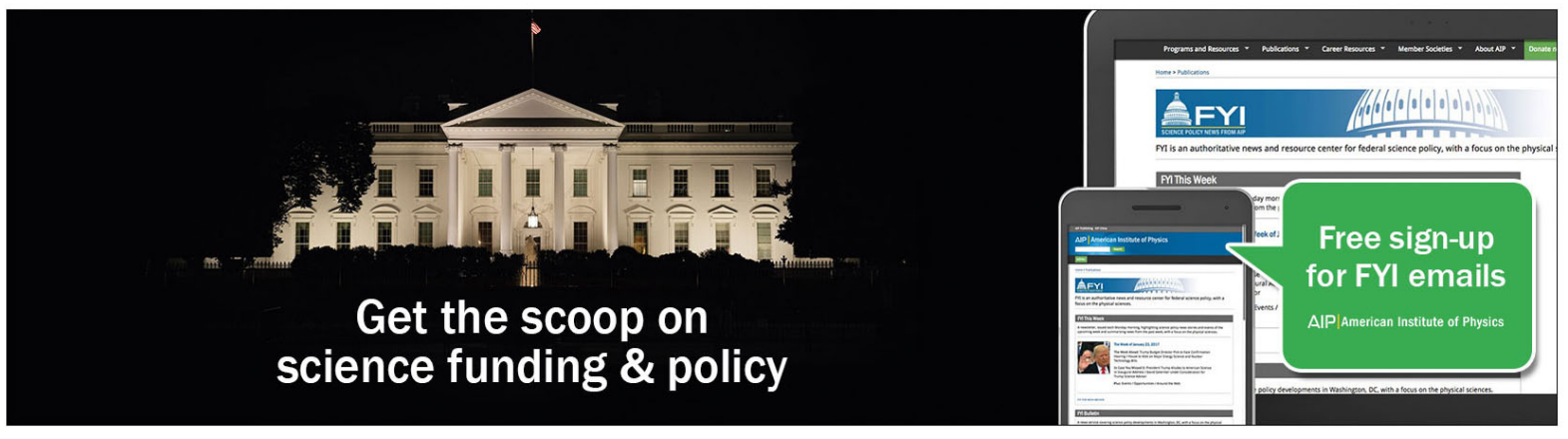




\title{
Catastrophic degradation of the interface of epitaxial silicon carbide on silicon at high temperatures
}

\author{
Aiswarya Pradeepkumar, ${ }^{1}$ Neeraj Mishra, ${ }^{1}$ Atieh Ranjbar Kermany, ${ }^{1}$ John J. Boeckl, ${ }^{2}$ \\ Jack Hellerstedt, ${ }^{3}$ Michael S. Fuhrer, ${ }^{3}$ and Francesca lacopi ${ }^{1}$ \\ ${ }^{1}$ Queensland Micro and Nanotechnology Centre and Environmental Futures Research Institute, \\ Griffith University, Nathan QLD 4111, Australia \\ ${ }^{2}$ Materials and Manufacturing Directorate, Air Force Research Laboratories, Wright-Patterson \\ Air Force Base, Ohio 45433, USA \\ ${ }^{3}$ Monash Centre for Atomically Thin Materials, Monash University, Monash, VIC 3800, Australia
}

(Received 24 March 2016; accepted 24 June 2016; published online 6 July 2016)

\begin{abstract}
Epitaxial cubic silicon carbide on silicon is of high potential technological relevance for the integration of a wide range of applications and materials with silicon technologies, such as micro electro mechanical systems, wide-bandgap electronics, and graphene. The hetero-epitaxial system engenders mechanical stresses at least up to a GPa, pressures making it extremely challenging to maintain the integrity of the silicon carbide/silicon interface. In this work, we investigate the stability of said interface and we find that high temperature annealing leads to a loss of integrity. High-resolution transmission electron microscopy analysis shows a morphologically degraded $\mathrm{SiC} / \mathrm{Si}$ interface, while mechanical stress measurements indicate considerable relaxation of the interfacial stress. From an electrical point of view, the diode behaviour of the initial $\mathrm{p}-\mathrm{Si} / \mathrm{n}-\mathrm{SiC}$ junction is catastrophically lost due to considerable inter-diffusion of atoms and charges across the interface upon annealing. Temperature dependent transport measurements confirm a severe electrical shorting of the epitaxial silicon carbide to the underlying substrate, indicating vast predominance of the silicon carriers in lateral transport above $25 \mathrm{~K}$. This finding has crucial consequences on the integration of epitaxial silicon carbide on silicon and its potential applications. Published by AIP Publishing. [http://dx.doi.org/10.1063/1.4955453]
\end{abstract}

Epitaxial cubic silicon carbide $(\mathrm{SiC})$ films on silicon have attracted extensive interest in many semiconductor device applications such as high-voltage, high-frequency diodes, hetero-junction bi-polar transistors and micro electro mechanical systems (MEMS). ${ }^{1,2}$ This is because they offer access to the electrical and mechanical properties of the $\mathrm{SiC}$ material such as its wide band gap, high thermal conductivity, and chemical stability, in addition to a large tuneable tensile stress. ${ }^{1,3}$ However, the large lattice and thermal mismatches between the $\mathrm{SiC}$ film and silicon result in a high density of defects $^{4}$ and a sharp residual stress gradient at the $\mathrm{SiC} / \mathrm{Si}$ interface. ${ }^{5}$ Consequently, non-ideal diode characteristics have been observed for the common $\mathrm{n}-\mathrm{SiC} / \mathrm{p}-\mathrm{Si}$ electronic junction, which poses concerns for the reliability of $3 \mathrm{C}-\mathrm{SiC}$ devices. ${ }^{1,4,6-9}$

Tanner et al. have characterized the as-grown n-3C-SiC/ p-Si hetero-junctions and have demonstrated a strong interface with reverse bias breakdown voltages exceeding $200 \mathrm{~V}$, and $\pm 1 \mathrm{~V}$ rectification ratio of 200000 at room temperature. ${ }^{1}$ However, the stability of the interface at higher temperatures, which is relevant for the synthesis of graphene on 3C$\mathrm{SiC} / \mathrm{Si}^{10}{ }^{10} \mathrm{GaN}$ on $\mathrm{SiC} / \mathrm{Si}^{11}$ and for harsh-environment applications of the $\mathrm{SiC} / \mathrm{Si}^{12}$ has not yet been investigated to-date.

In this work, we evaluate the stability of the $\mathrm{SiC} / \mathrm{Si}$ hetero-junction at high temperatures by performing stress, electronic transport measurements, and high-resolution microscopy of the $\mathrm{SiC} / \mathrm{Si}$ interface. We show that high temperatures have catastrophic consequences on the $\mathrm{SiC} / \mathrm{Si}$ junction.

Unintentionally $n$-type doped epitaxial 3C-SiC films with thickness of $250 \mathrm{~nm}$ were grown in-house at $1000^{\circ} \mathrm{C}$ on low-doped $6^{\prime \prime}$ wafers of $p$-type $\mathrm{Si}(100)$ and $\mathrm{Si}(111)$ with thickness of $680 \pm 25 \mu \mathrm{m}$ in a hot-wall horizontal Low-Pressure Chemical Vapour Deposition (LPCVD) system using an alternate supply of $\mathrm{SiH}_{4}$ and carbon source gas, described in previous reports. ${ }^{4,13}$ The carbonisation was performed at $950{ }^{\circ} \mathrm{C}$ using $\mathrm{C}_{2} \mathrm{H}_{2}$.

For the electrical characterization, $\mathrm{SiC} / \mathrm{Si}$ wafers were diced into $1 \times 1 \mathrm{~cm}^{2}$ fragments. For measurements with setup 1 (Griffith University), $150 \mathrm{~nm}$ nickel contacts were sputtered on the four corners of the aforementioned samples. The electrical properties such as the carrier concentration, carrier mobility, and sheet resistance were estimated at room temperature by performing Hall measurements in a van der Pauw configuration on the as-grown $\mathrm{SiC}(100)$ films, with electrical probes directly connected with the metal contacts and sweeping the DC input current of 0 to $10 \mathrm{~mA}$ using a HP4145B semiconductor parameter analyser. ${ }^{10}$ Analogous $\mathrm{SiC}(100)$ films were annealed at $1100^{\circ} \mathrm{C}$ using a Carbolite High Temperature Furnace at $10^{-4}$ mbar for $1 \mathrm{hr}$, and the electrical measurements were repeated at room temperature on the annealed $\mathrm{SiC}$ films. Complementary measurements were also carried out on the $1 \times 1 \mathrm{~cm}^{2}$ fragments of the bare silicon substrate. Additionally, equivalent electrical measurements at room temperature were performed on $1 \times 1 \mathrm{~cm}^{2}$ fragments of commercially available, unintentionally $n$-type doped NOVASiC $\mathrm{SiC}(100)$ grown at $1350{ }^{\circ} \mathrm{C}$ after a carbonisation step at $1100^{\circ} \mathrm{C}^{14}$

The temperature-dependent transport measurements of the as-grown and the annealed in-house $\mathrm{SiC}(100)$ films were performed with a Quantum Design PPMS (subsequently referred to as "setup 2"). $1 \times 1 \mathrm{~cm}^{2}$ fragments of $\mathrm{SiC}$ wafers with $(5 / 50 \mathrm{~nm}) \mathrm{Ti} / \mathrm{Au}$ contacts on the four corners in the van 
der Pauw geometry were used. In instances of poor wire bond adhesion, silver epoxy was used to make electrical connection to the samples. Two probe current-voltage curves were measured to ensure ohmic contact. The measurements were carried out as a function of temperature in the range between $5 \mathrm{~K}$ and $300 \mathrm{~K}$. Hall carrier density values were measured by sweeping the magnetic field $\pm 0.1 \mathrm{~T}$, symmetrizing the measured $\mathrm{R}_{\mathrm{xy}}$ response and fitting the linear slope to extract the carrier density. The temperature-dependent resistivity is used to estimate the ionization energy of dopants in the samples (see below). High-resolution transmission electron microscopy (HRTEM) was performed to characterize the $\mathrm{SiC} / \mathrm{Si}$ interface of the as-grown and the annealed $\mathrm{SiC}(100)$ and $\mathrm{SiC}(111)$ films using a FEI Tecnai F30 system operating at $200 \mathrm{keV} .{ }^{4}$ Sample foils for transmission electron microscopy were prepared via a focused ion beam (FIB) liftout technique using a FEI Strata DB235 FIB/SEM with a $\mathrm{Ga}^{+}$ion source. The foils were excavated from the bulk samples and thinned to about $500 \mathrm{~nm}$. Subsequently, $\mathrm{Ar}^{+}$ion milling was conducted in a Fiscione NanoMill ${ }^{\mathrm{TM}}$ to remove $\mathrm{Ga}^{+}$ion damage. A $2 \mu \mathrm{m}$ thick $\mathrm{Pt} / \mathrm{Au}$ protective layer was deposited on the samples prior to FIB milling.

We also conducted a residual in-plane stress analysis on the as-grown and annealed in-house $\mathrm{SiC}$ films via full wafer curvature measurement. 3C-SiC(100) and 3C-SiC(111) films grown with different thicknesses on full 6 " silicon wafers were used for the study. A Tencor Flexus 2320 system was used for measuring the wafer curvature of the $\mathrm{Si}$ substrate and the substrate-film composite at room temperature. ${ }^{4}$ The residual in-plane stress for the $\mathrm{SiC}$ film was calculated using the modified Stoney's equation with appropriate elastic moduli (E) and Poisson's ratio $(\nu)$ values: $130 \mathrm{GPa}$ and $170 \mathrm{GPa}$, 0.28 and 0.26 for $\mathrm{Si}(100)$ and $\mathrm{Si}(111)$, respectively., ${ }^{4,5}$ Subsequently, the as-grown films were subjected to thermal annealing in $\mathrm{N}_{2}$ at different temperatures of $1100^{\circ} \mathrm{C}$, $1180^{\circ} \mathrm{C}$, and $1250^{\circ} \mathrm{C}$ for $2 \mathrm{hrs}$. This was done in a Hi-Tech Furnace Systems (UK) LPCVD system at sub-atmospheric pressure of $10-1000 \mathrm{~Pa}^{5}$ From the residual stress values of the as-grown and the annealed film, the absolute stress difference (MPa) between them was assessed.

Table I shows the room temperature van der Pauw measurement results of the as-grown and the annealed $\mathrm{SiC}(100)$ samples obtained with setup 1 . The as-grown $\mathrm{SiC}(100)$ indicates $n$-type conduction with sheet carrier concentration $\left(\mathrm{n}_{\mathrm{s}}\right)$, carrier mobility $\left(\mu_{\mathrm{s}}\right)$, and sheet resistance $\left(\mathrm{R}_{\mathrm{s}}\right)$ of $3.3( \pm 0.2) \times 10^{14} \mathrm{~cm}^{-2}$, $14( \pm 10) \mathrm{cm}^{2} / \mathrm{V} \mathrm{s}$, and $1354 \pm 1 \Omega / \square$, respectively.

Upon annealing, the sample shows an abrupt switch to $p$-type conduction with a $\mathrm{n}_{\mathrm{s}} \sim 3$ times larger than that of the asgrown sample. In addition, the mobility increases significantly

TABLE I. Electrical characteristics measured at room temperature for inhouse $\mathrm{SiC} / \mathrm{Si}(100)$ samples as-grown and after annealing at $1100^{\circ} \mathrm{C}$ (data acquired with setup 1).

\begin{tabular}{lcc}
\hline \hline & As-grown & Annealed \\
\hline Carrier type & Electrons & Holes \\
Sheet carrier concentration, $\mathrm{n}_{\mathrm{s}}\left(\mathrm{cm}^{-2}\right)$ & $3.3( \pm 0.2) \times 10^{14}$ & $9.5( \pm 0.2) \times 10^{14}$ \\
Mobility, $\mu_{\mathrm{s}}\left(\mathrm{cm}^{2} / \mathrm{V} \mathrm{s}\right)$ & $14( \pm 10)$ & $273( \pm 10)$ \\
Sheet resistance, $\mathrm{R}_{\mathrm{s}}(\Omega / \square)$ & $1354 \pm 1$ & $24 \pm 1$ \\
\hline \hline
\end{tabular}

from $14 \mathrm{~cm}^{2} / \mathrm{V}$ s to $273 \mathrm{~cm}^{2} / \mathrm{V} \mathrm{s}$, accompanied by a drastic decrease of the $R_{s}$ of the sample down to $24 \Omega / \square$. These room temperature values are in good agreement with those obtained from setup 2, at Monash University.

Complementary room temperature measurements of the bare silicon substrate indicate $p$-type conduction with a sheet carrier concentration of $\sim 9 \times 10^{13} \mathrm{~cm}^{-2}$, from which a bulk carrier concentration of $\sim 1.3 \times 10^{15} \mathrm{~cm}^{-3}$ is estimated, and a mobility of $\sim 341 \mathrm{~cm}^{2} / \mathrm{V} \mathrm{s}$.

We thus hypothesize that the switch to $p$-type carriers, increase in mobility, and drop in sheet resistance are due to a shorting of the $\mathrm{SiC}$ film to the substrate upon annealing with consequent dominance of the carriers in the thick silicon substrate, with relatively high mobility. If we considered the annealed SiC sample in Table I as an electrically shorted substrate plus film composite, we would estimate a bulk sheet carrier concentration of $1.5 \times 10^{16} \mathrm{~cm}^{-3}$. This is an order of magnitude higher than the bulk carrier concentration directly measured on the silicon substrate, which is plausible as a result of the combined carrier contributions from both silicon substrate and the silicon carbide. ${ }^{15}$

Further corroborating this hypothesis, the as-grown unintentionally doped (thus n-type) commercial NovaSiC $\mathrm{SiC}$ films on p-type $\mathrm{Si}(100)$ show the unexpected p-type conduction already when measured at room temperature, with $\mathrm{n}_{\mathrm{s}}, \mu_{\mathrm{s}}$, and $\mathrm{R}_{\mathrm{s}}$ of $1 \times 10^{14} \mathrm{~cm}^{-2}, 272 \mathrm{~cm}^{2} / \mathrm{V} \mathrm{s}$, and $180 \Omega / \square$, respectively. When grown on $n$-type substrates instead, these films always show $n$-type conduction. This indicates that the transport characteristics of the commercial samples may be dominated by the substrate already as-grown. Note that such samples are grown at a much higher temperature of $1350{ }^{\circ} \mathrm{C} .{ }^{14}$

The low-temperature transport measurements were performed on the $\mathrm{SiC}$ films grown in-house for a more detailed analysis. Figure 1 illustrates the low temperature behaviour of the sheet resistance of the as-grown and the annealed $\mathrm{SiC}(100)$ as a function of temperature in the range between

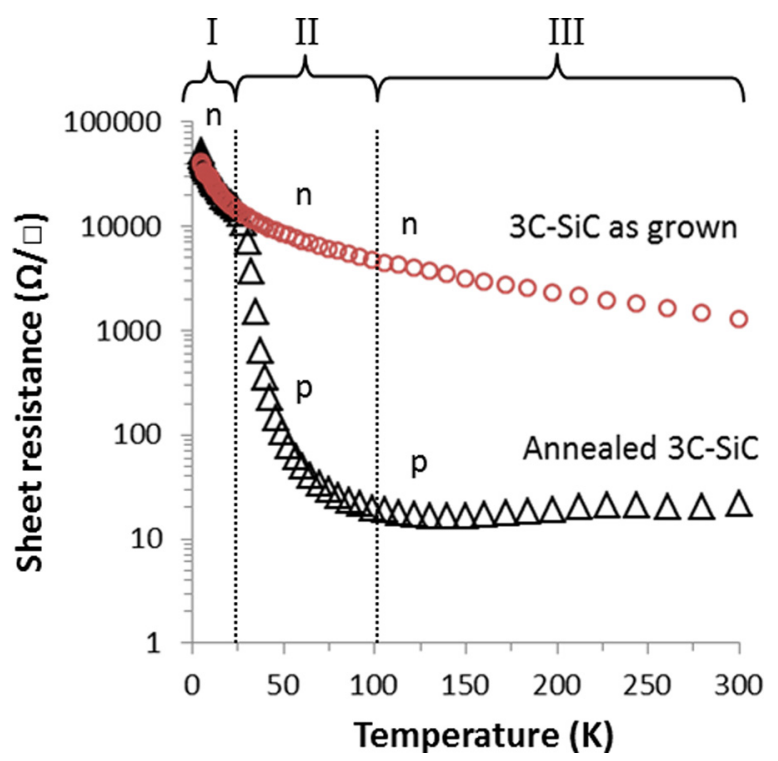

FIG. 1. Sheet resistance of the $250 \mathrm{~nm}$ thick as-grown $\mathrm{SiC}(100)$ and the vacuum annealed $\mathrm{SiC}(100)$ at $1100^{\circ} \mathrm{C}$ for $1 \mathrm{hr}$ as a function of temperature in the range between $5 \mathrm{~K}$ and $300 \mathrm{~K}$. 
$5 \mathrm{~K}$ and $300 \mathrm{~K}$. The sheet resistance of the as-grown $\mathrm{SiC}$ film decreases monotonically with temperature. From basic solid state theory, the resistivity of a semiconductor versus temperature would decrease according to an Arrhenius type behaviour $^{16,17}$ such as

$$
\rho \propto T^{3 / 2} \exp \left(\frac{E_{a}}{2 k_{\mathrm{B}} T}\right),
$$

where $\rho$ is the resistivity, $\mathrm{k}_{\mathrm{B}}$ is the Boltzmann constant, $\mathrm{T}$ is the absolute temperature, and $\mathrm{E}_{\mathrm{a}}$ is the activation energy of the semiconductor. In particular, for $\mathrm{k}_{\mathrm{B}} \mathrm{T}$ far below the bandgap of the semiconductor, the activation energy dominating the resistivity behaviour is the donor (for $n$-type) or acceptor (for $p$-type) energy level for the specific dopant.

In hetero-epitaxial $\mathrm{SiC}$ on silicon, it is notoriously hard to identify a specific dopant level as the resistivity is affected by a combination of different unintentional defects, including $\mathrm{N}$ incorporation. ${ }^{18}$ Indeed, by fitting the as-grown $\mathrm{SiC}$ resistance behaviour, we confirmed the presence of different donor contributions with energy levels approximately varying from $2 \mathrm{meV}$ to $52 \mathrm{meV}$ (extracted using Equation (1)) over the studied temperature range as reported in the literature. ${ }^{18}$

On the other hand, the annealed $\mathrm{SiC}(100)$ indicates a more complex behaviour within the same temperature range. For temperatures below $\sim 25 \mathrm{~K}$ (zone I), its behaviour matches with that of the as-grown $\mathrm{SiC}$, including the presence of a majority of $n$-type carriers. However, just above $\sim 25 \mathrm{~K}$, a change in majority carriers to $p$-type is observed, concomitant with a sharp decrease in sheet resistance of several orders of magnitude (zone II). In zone II, this sample shows the typical decreasing resistance behaviour versus temperature expected for a semiconductor with different donor/acceptor characteristics. Above 150-200 K (zone III), the annealed sample shows an increase in resistivity, associated with a predominance of phonon scattering, while continuing to exhibit prevalent $p$-type conduction.

Fig. 2 shows the fitted resistivity for the annealed $\mathrm{SiC}$ as a function of temperature in the range from $30 \mathrm{~K}$ to $100 \mathrm{~K}$ (zone II), with slope $=0.11$. The extracted acceptor energy

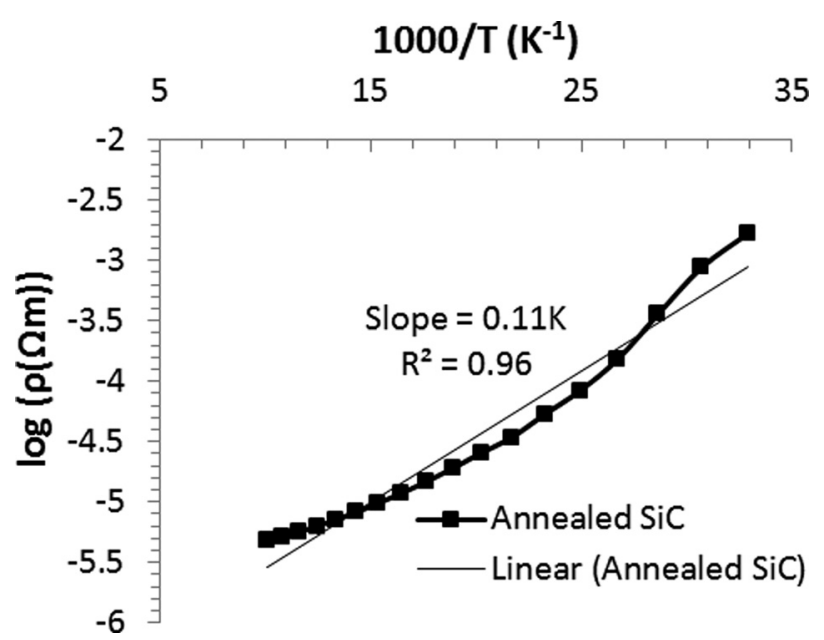

FIG. 2. Resistivity versus temperature for the annealed $\mathrm{SiC}(100)$. Activation energy of $44 \mathrm{meV}$ is obtained by fitting the data over $30 \mathrm{~K}$ to $100 \mathrm{~K}$ (zone II). level using Equation (1) is about $44 \mathrm{meV}$, which is consistent with the boron acceptor energy level in silicon $(46 \mathrm{meV}){ }^{19}$ Note that this was calculated through an approximated expression of Eq. (1) where the power dependence of the temperature was neglected, an adequate approximation for low temperatures.

The data in Fig. 1 indicate that while the resistivity of the as-grown $\mathrm{SiC} / \mathrm{Si}(100)$ matches what is expected for an $n$-type 3C-SiC semiconductor film, the behaviour of the annealed $\mathrm{SiC} / \mathrm{Si}(100)$ matches with that of $3 \mathrm{C}-\mathrm{SiC}$ only for temperatures below $25 \mathrm{~K}$. Above $25 \mathrm{~K}$, (zone II) the resistance behaviour closely resembles the one expected from silicon (see the extracted energy level). The fact that above $25 \mathrm{~K}$ the majority carrier type conduction switches abruptly from $n$ - to $p$-type is a further strong indication that the silicon substrate dominates the conduction in the annealed $\mathrm{SiC} / \mathrm{Si}$ in zones II and III, including room temperature. This all would indeed point to a system in which the conduction of the thin film $\mathrm{SiC}$ and that of the silicon substrate are highly intermixed, appearing electrically shorted. The $p$-type conduction within the thick silicon substrate clearly dominates until between $50 \mathrm{~K}$ and $25 \mathrm{~K}$ where a substantial freeze-out of the boron dopants in the silicon matrix is reached..$^{20}$ Note that the total number of carriers in the silicon substrate and in the $\mathrm{SiC}$ film are comparable, but the $p$-type carriers in the silicon show much higher mobility, so they dominate the system above the B dopant freeze-out temperature. Therefore, we find that the $n$-type conduction of the $\mathrm{SiC}$ film is the prevalent measured signal only below $25 \mathrm{~K}$.

If the carbonisation layer, which serves as the sealing layer for the out-diffusion of silicon, develops substantial discontinuities, this would allow for extensive charge diffusion at the $\mathrm{SiC} / \mathrm{Si}$ interface with consequent loss of the $n-p$ junction.

If this were the case, the degradation of the interface would likely be accompanied by a relaxation of interfacial stress. Table II shows residual mean stress (MPa) and absolute stress differences (MPa) of $\mathrm{SiC}(100)$ and $\mathrm{SiC}(111)$ films of thickness ranging between $50 \mathrm{~nm}$ and $1 \mu \mathrm{m}$, before and after annealing at different temperatures above the $\mathrm{SiC}$ growth temperature.

We have already reported ${ }^{5}$ that the as-grown $3 \mathrm{C}-\mathrm{SiC}$ films on Si show tensile mean residual stress due to the lattice and thermal mismatches. From Table II, we can observe that, when the thin films of SiC are thermally annealed, the stresses tend to become more compressive. The extent of the change upon annealing is given by the absolute stress difference (MPa) in Fig. 3, and it appears to be strongly dependent on the film thickness. In particular, the largest difference is found for the thinnest films, for both $\mathrm{SiC}(100)$ and $\mathrm{SiC}(111)$.

In addition, Table II shows that, not surprisingly, the extent of stress change also depends on the annealing temperature: higher annealing temperatures lead to a larger change. For example, the $49 \mathrm{~nm}$ thick $\mathrm{SiC}(100)$ data shown led to an absolute stress difference of $532 \mathrm{MPa}$ when annealed at $1180^{\circ} \mathrm{C}$ while annealing at $1250^{\circ} \mathrm{C}$ caused a larger stress difference of $762 \mathrm{MPa}$. The absolute stress differences between the as-grown and annealed samples as a function of the film thickness is plotted in Fig. 3. All the samples shown here are annealed at $1180^{\circ} \mathrm{C}$ in $\mathrm{N}_{2}$ for $2 \mathrm{hrs}$. 
TABLE II. Residual mean stresses $(\sigma)$ for the as-grown and annealed $\mathrm{SiC}(100)$ and $\mathrm{SiC}(111)$ films and the absolute stress differences between them. The films are of different thicknesses and annealed in $\mathrm{N}_{2}$ for $2 \mathrm{hrs}$ at different temperatures of $1100^{\circ} \mathrm{C}, 1180^{\circ} \mathrm{C}$, and $1250^{\circ} \mathrm{C}$.

\begin{tabular}{|c|c|c|c|c|c|c|}
\hline \multirow[b]{2}{*}{ Sample no. } & \multirow[b]{2}{*}{ Thickness $(\mathrm{nm} \pm 2 \mathrm{~nm})$} & \multirow[b]{2}{*}{$\sigma_{\text {as-grown }}(\mathrm{MPa})$} & \multicolumn{3}{|c|}{$\sigma_{\text {anneal }}(\mathrm{MPa})$} & \multirow[b]{2}{*}{ Absolute stress differences (MPa) } \\
\hline & & & $1100^{\circ} \mathrm{C}$ & $1180^{\circ} \mathrm{C}$ & $1250^{\circ} \mathrm{C}$ & \\
\hline \multicolumn{7}{|l|}{$\mathrm{SiC}(100)$} \\
\hline 1 & 49 & 424 & & -108 & & 532 \\
\hline 2 & 49 & 363 & & & -399 & 762 \\
\hline 3 & 66 & 302 & 129 & & & 173 \\
\hline 4 & 67 & 288 & & -28 & & 315 \\
\hline 5 & 67 & 322 & & & -208 & 530 \\
\hline 6 & 92 & 323 & & 133 & & 190 \\
\hline 7 & 92 & 291 & & & -15 & 306 \\
\hline 8 & 270 & 187 & & 147 & & 39 \\
\hline 9 & 300 & 305 & & 273 & & 31 \\
\hline 10 & 348 & 308 & & 297 & & 11 \\
\hline 11 & 994 & 151 & & 153 & & -3 \\
\hline \multicolumn{7}{|l|}{$\operatorname{SiC}(111)$} \\
\hline 1 & 50 & 423 & & -462 & & 885 \\
\hline 2 & 53 & 616 & & & -563 & 1179 \\
\hline 3 & 69 & 856 & 735 & & & 121 \\
\hline 4 & 70 & 1034 & 891 & & & 143 \\
\hline 5 & 69 & 467 & & -120 & & 586 \\
\hline 6 & 70 & 840 & & 439 & & 401 \\
\hline 7 & 71 & 590 & & & -203 & 794 \\
\hline 8 & 90 & 458 & & 100 & & 358 \\
\hline 9 & 95 & 644 & & & 90 & 554 \\
\hline 10 & 238 & 524 & & 442 & & 82 \\
\hline 11 & 300 & 915 & & 852 & & 63 \\
\hline 12 & 945 & 679 & & 672 & & 7 \\
\hline
\end{tabular}

These data indicate that the absolute stress differences after annealing for $\mathrm{SiC}(100)$ and $\mathrm{SiC}(111)$ are of a similar magnitude. Furthermore, the thickness dependence clearly indicates suppression of the stress change with increasing thickness, with samples on the order of $1 \mu \mathrm{m}$ showing virtually no change with annealing. The strong reduction in stress change when moving away from the interface indicates that this is an interfacial stress dominated phenomenon. Note that

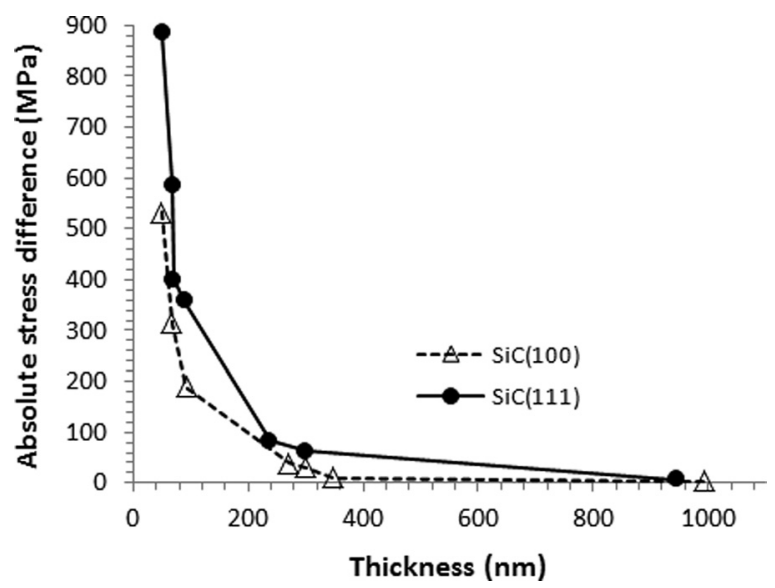

FIG. 3. Absolute stress difference of the epitaxial $\mathrm{SiC}(100)$ and $\mathrm{SiC}(111)$ films before and after annealing at $1180^{\circ} \mathrm{C}$ versus film thickness. Each point represents the absolute difference of the average stress for the as-grown and the annealed films. The difference indicates in all cases a transition towards a more compressive stress state with decreasing thickness. Note that the exponential suppression of the stress difference with increasing thickness indicates the interfacial nature of the stress change. as a result of this stress relaxation at the $\mathrm{SiC} / \mathrm{Si}$ interface, we observed plastic relaxation of the substrate after annealing, leading to a change in the bare substrate wafer curvature to more convex. The values of $\sigma_{\text {anneal }}$ in Table II were not corrected for this change, so that the stress changes in Fig. 3 are in fact a measure of the overall $\mathrm{SiC} / \mathrm{Si}$ interface relaxation. Finally, we note that that the occurrence of plastic deformation of the silicon substrate was reported by Zielinski et al., when growing $\mathrm{SiC}$ at high temperatures. ${ }^{22}$

Cross sectional transmission electron microscopy focusing on comparing the $\mathrm{SiC} / \mathrm{Si}$ interface of as-grown and $\mathrm{SiC}$ films annealed at $1100{ }^{\circ} \mathrm{C}$ should likely indicate morphological changes.

Fig. 4 shows that both the as-grown $3 \mathrm{C}-\mathrm{SiC}(100)$ and $\mathrm{SiC}(111)$ films possesses a very thin, well defined $\sim 1 \mathrm{~nm}$ thick carbonisation layer at the interface. On the other hand, it is evident that, after annealing, the $\mathrm{SiC} / \mathrm{Si}$ interface degraded, appearing inhomogeneous in the TEM image.

All of these data indicate a substantial degradation of the interface as failure mode, a consequence of the combination of high temperatures and high stresses at the $\mathrm{SiC} / \mathrm{Si}$ interface. A substantial amount of stress is relaxed at the $\mathrm{SiC} / \mathrm{Si}$ interface by allowing substantial atomic interdiffusion between the $\mathrm{SiC}$ and the silicon substrate. Here, we indicate that the carbonisation barrier can already break down at temperatures roughly above $1000-1100^{\circ} \mathrm{C}$, although the exact temperature may slightly shift depending on the carbonisation processes. This effect is so prominent that the insulating $\mathrm{n}-\mathrm{SiC} / \mathrm{p}-\mathrm{Si}$ junction is destroyed and the 

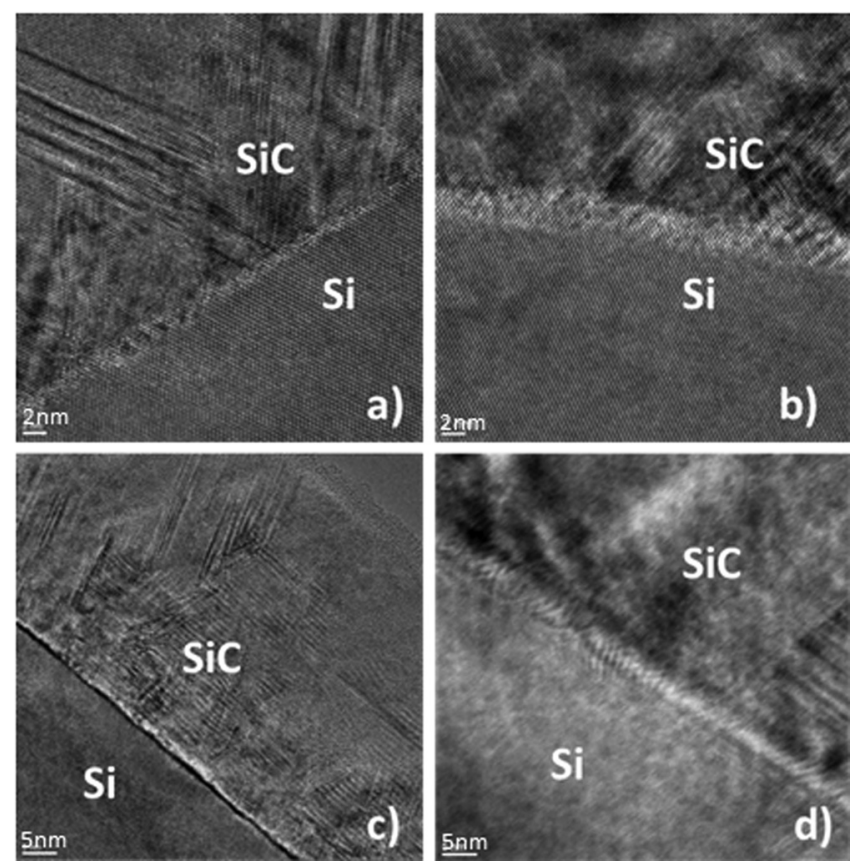

FIG. 4. High-resolution TEM micrographs of the SiC-Si interface of the $250 \mathrm{~nm}$-thick $\mathrm{SiC}(100)$ and $\mathrm{SiC}(111)$ films (a) as-grown $\mathrm{SiC}(100)$ film (b) $\mathrm{SiC}(100)$ film annealed in vacuum at $1100^{\circ} \mathrm{C}$, for $1 \mathrm{hr}$ (c) as-grown $\mathrm{SiC}(111)$ film (d) $\mathrm{SiC}(111)$ film annealed in vacuum at $1100^{\circ} \mathrm{C}$, for $1 \mathrm{hr}$. The $\mathrm{SiC} / \mathrm{Si}$ interface of both the as-grown $\mathrm{SiC}$ films appears to be well-defined, whereas the interface of the annealed $\mathrm{SiC}$ films appears inhomogeneous.

layer-substrate system becomes electrically shorted to the substrate.

Such fatal failure can occur both upon film growth at high temperature (NovaSiC) and annealing at high temperature (in-house films). The detailed description of the failure mechanisms will be strongly dependent on the specific sample preparation. Here, we suggest some plausible root causes. The interface layer of the in-house $\mathrm{SiC}$ films on silicon possesses about a GPa of compressive stress. ${ }^{5}$ That alone could lead to failure at high temperatures because of enhanced creep effects. ${ }^{21}$ For the commercial samples, this is potentially compounded by the additional compressive thermal stress $^{23}$ of the thin carbonisation layer when brought to $1350^{\circ} \mathrm{C}$ for the $\mathrm{SiC}$ growth and increased $\mathrm{Si}$ out-diffusion at such temperature, only $\sim 60^{\circ} \mathrm{C}$ lower than the silicon melting temperature. The silicon out-diffusion from silicon substrate to the silicon carbide at high temperatures in the absence of an efficient diffusion barrier is a well-known issue. $^{24,25}$ The occurrence of creep via atomic diffusion at the $\mathrm{SiC} / \mathrm{Si}$ interface was likely already observed earlier. ${ }^{22}$

The $\mathrm{SiC} / \mathrm{Si}$ interface instability has crucial consequences on applications where the silicon carbide on silicon is exposed to high temperatures. In particular, this affects not only the use of $\mathrm{SiC}$ on silicon for harsh environments, but also the use of $\mathrm{SiC}$ on silicon as pseudo-substrate for the growth of III-N and graphene on silicon, as those materials are currently grown at temperatures above $1000^{\circ} \mathrm{C}$. Therefore, we indicate a compelling need to identify a more robust barrier at the $\mathrm{SiC} / \mathrm{Si}$ interface able to insulate the silicon carbide from the silicon substrate at high temperatures. ${ }^{24}$

F.I. is the recipient of an Australian Research Council Future Fellowship (FT120100445). The support from the AFOSR through the Grant No. AOARD 15IOA053 is also acknowledged, as well as infrastructure support through the Australian National Fabrication Facility (ANFF). J.H. and M.S.F. are supported by ARC DP150103837.

${ }^{1}$ P. Tanner, S. Dimitrijev, and H. B. Harrison, in Proceedings of Optoelectronic and Microelectronic Materials and Devices, 2008, COMMAD 2008 (IEEE, 2008), p. 41.

${ }^{2}$ M. I. Chaudhry, IEEE Electron Device Lett. 12(12), 670 (1991).

${ }^{3}$ X. Song, J. F. Michaud, F. Cayrel, M. Zielinski, M. Portail, T. Chassagne, E. Collard, and D. Alquier, Appl. Phys. Lett. 96(14), 142104 (2010).

${ }^{4}$ F. Iacopi, G. Walker, L. Wang, L. Malesys, S. Ma, B. V. Cunning, and A. Iacopi, Appl. Phys. Lett. 102(1), 011908 (2013).

${ }^{5}$ F. Iacopi, R. E. Brock, A. Iacopi, L. Hold, and R. H. Dauskardt, Acta Mater. 61, 6533 (2013).

${ }^{6}$ V. Cimalla, J. Pezoldt, and O. Ambacher, J. Phys. D: Appl. Phys. 40(20), 6386 (2007)

${ }^{7}$ N. Mishra, L. Hold, A. Iacopi, B. Gupta, N. Motta, and F. Iacopi, J. Appl. Phys. 115(20), 203501 (2014).

${ }^{8}$ A. R. Kermany and F. Iacopi, J. Appl. Phys. 118(15), 155304 (2015).

${ }^{9}$ A. R. Kermany, G. Brawley, N. Mishra, E. Sheridan, W. P. Bowen, and F. Iacopi, Appl. Phys. Lett. 104(8), 081901 (2014).

${ }^{10}$ F. Iacopi, N. Mishra, B. V. Cunning, D. Goding, S. Dimitrijev, R. Brock, R. H. Dauskardt, B. Wood, and J. Boeckl, J. Mater. Res. 30(05), 609 (2015).

${ }^{11}$ D. K. Wickenden, K. R. Faulkner, R. W. Brander, and B. J. Isherwood, J. Cryst. Growth 9, 158 (1971).

${ }^{12} \mathrm{M}$. Wijesundara and R. Azevedo, Silicon Carbide Microsystems for Harsh Environments (Springer Science \& Business Media, 2011).

${ }^{13}$ L. Wang, S. Dimitrijev, J. Han, A. Iacopi, L. Hold, P. Tanner, and H. B. Harrison, Thin Solid Films 519(19), 6443 (2011).

${ }^{14}$ M. Portail, M. Zielinski, T. Chassagne, S. Roy, and M. Nemoz, J. Appl. Phys. 105(8), 083505 (2009).

${ }^{15} \mathrm{C}$. Hurd, The Hall Effect in Metals and Alloys (Springer Science \& Business Media, 2012).

${ }^{16}$ R. E. Hummel, Electronic Properties of Materials (Springer Science \& Business Media, 2011).

${ }^{17}$ L. Solymar, D. Walsh, and R. R. Syms, Electrical Properties of Materials (OUP Oxford, 2014).

${ }^{18}$ H. Matsuura, Y. Masuda, Y. Chen, and S. Nishino, Jpn. J. Appl. Phys., Part 1 39(9R), 5069 (2000).

${ }^{19}$ N. W. Ashcroft and N. D. Mermin, Solid State Physics (Saunders College, Philadelphia, 1976).

${ }^{20}$ J. D. Cressler and H. A. Mantooth, Extreme Environment Electronics (CRC Press, 2012).

${ }^{21}$ F. Iacopi, S. H. Brongersma, and K. Maex, Appl. Phys. Lett. 82(9), 1380 (2003).

${ }^{22}$ M. Zielinski, A. Leycuras, S. Ndiaye, and T. Chassagne, Appl. Phys. Lett. 89, 131906 (2006).

${ }^{23}$ F. C. Marques, R. G. Lacerda, A. Champi, V. Stolojan, D. C. Cox, and S. R. P. Silva, Appl. Phys. Lett. 83(15), 3099 (2003).

${ }^{24}$ S. Jiao, Y. Murakami, H. Nagasawa, H. Fukidome, I. Makabe, Y. Tateno, T. Nakabayashi, and M. Suemitsu, Mater. Sci. Forum 806, 89 (2014).

${ }^{25}$ N. Becourt, J. L. Ponthenier, A. M. Papon, and C. Jaussaud, Phys. B: Condens. Matter 185(1), 79 (1993). 